\title{
The Uricosuric Effect in Rats of E5050, a New Derivative of Ethanolamine, Involves Inhibition of the Tubular Postsecretory Reabsorption of Urate
}

\author{
Haruko Sugino and Hideyo Shimada \\ Department of Clinical Pharmacology, School of Pharmaceutical Sciences, Kitasato University, 5-9-1 Shirokane, Minato-ku, Tokyo 108, Japan \\ Received January 27, 1995 Accepted April 20, 1995
}

\begin{abstract}
N-\left\{3-\left[4^{\prime}-\left(2^{\prime \prime}, 6\right.\right.\right.$ '-Dimethylheptyl)phenyl]butanoyl $\}$ ethanolamine (E5050), a newly synthesized compound, was shown recently to induce uricosuria in humans via inhibition of the postsecretory reabsorption of urate. We examined the effects of this compound on urate excretion in rats loaded with oxonate and compared these effects with those of the uricosuric drugs trichlormethiazide and probenecid. When administered i.p., E5050 $(0.3-15 \mathrm{mg} / \mathrm{kg})$ increased the urinary excretion rate of urate and the ratio of urate clearance to inulin clearance in a dose-dependent manner, while the urine volume increased only slightly, and the glomerular filtration rate and plasma urate level were not changed. No paradoxical effect on urate excretion was observed. In contrast, trichlormethiazide and probenecid had a biphasic effect on urate excretion. In a pyrazinoic acid suppression test, the uricosuric effect of E5050 was completely inhibited by pretreatment with pyrazinoic acid. In a phenolsulfonphthalein (PSP) test, E5050 did not affect urinary PSP excretion, while probenecid strongly decreased such excretion. Thus, E5050 also appears to be uricosuric in rats.
\end{abstract}

Keywords: E5050, Uricosuric drug, Pyrazinoic acid, Phenolsulfonphthalein, Urate excretion

The renal handling of urate can be explained by the four-component theory (1); That is, plasma urate is filtered from the blood at the glomerulus and subsequently undergoes presecretory reabsorption, secretion and postsecretory reabsorption at the renal tubule. This theory is not applicable in a similar manner to all species. The extent of the contribution of each of the above four processes to urate excretion shows differences among species. Uricosuria is the result of the sum of the consequences of reabsorption and secretion. Moreover, animals can be roughly separated into two groups: one group, including rabbits and pigs, shows net tubular secretion; the other group, including humans, Cebus monkeys and rats, shows net tubular reabsorption (2). In the latter group, many uricosuric drugs, most of which are organic acids, exert their uricosuric effects by inhibition of reabsorption and, in part, by stimulation of urate secretion. For example, probenecid and tienilic acid, which are typical uricosuric drugs, inhibit pre- and postsecretory reabsorption, non-selectively (3); sulfinpyrazone inhibits urate reabsorption and also stimulates the secretion of urate (4). Thus, these uricosuric drugs have multiple effects on the tubular transport of urate.

In contrast to the above-described drugs, only a few drugs seem to exert a uricosuric action by the selective inhibition of the presecretory or postsecretory reabsorption of urate. Such drugs include AA-193 (5), a newly developed inhibitor of presecretory reabsorption, and benzbromarone $(1,6)$, a typical inhibitor of postsecretory reabsorption. Although benzbromarone is a potent uricosuric drug that is used clinically, there are fewer studies in animals and in vitro of this drug as compared to probenecid. Moreover, the reported uricosuric responses of rats to this drug varied among studies $(5,7)$ for unknown reasons. For a full understanding of mechanisms of uricosuric effects, we need to expand the list of selective inhibitors of urate excretion.

$N$-\{3-[4'-(2",6"-Dimethylheptyl) phenyl] butanoyl $\}$ etha nolamine (E5050), a compound synthesized as an antihyperlipidemic drug by Esai Co. (Tokyo) (8), was shown recently to have a uricosuric effect in humans, and the uricosuric activity of this drug was suggested to be due to inhibition of the postsecretory reabsorption of urate (9). However, no information is available on the uricosuric 
effects of E5050 in animals other than humans. Therefore, the present study with oxonate-loaded rats was performed to determine whether E5050 is also uricosuric in rats. An attempt was then made to determine the site of action of the drug in the rat renal tubule.

\section{MATERIALS AND METHODS}

\section{Animals and drugs}

Male Wistar rats weighing $270-280 \mathrm{~g}$ were used. The animals were housed in a temperature- $\left(23 \pm 1^{\circ} \mathrm{C}\right)$ and humidity- $(55 \pm 5 \%)$ controlled room with free access to food and water.

E5050 was a gift from Eisai Co. Other drugs used were potassium oxonate and pyrazinoic acid (Aldrich, Milwaukee, WI, USA), probenecid and trichlormethiazide (Sigma, St. Louis, MO, USA), and phenolsulfonphthalein (PSP; Phenolsulfonphthalein inj. Daiichi; Daiichi Pharmaceutical Co., Tokyo).

E5050 (0.3, 3, 10 or $15 \mathrm{mg})$ and trichlormethiazide $(0.1$ or $0.3 \mathrm{mg}$ ) were dissolved in $0.35 \mathrm{ml}$ of dimethyl sulfoxide (DMSO) and dispersed in $0.65 \mathrm{ml}$ of saline. Probenecid was suspended in a $1 \%$ solution of gum arabic. Pyrazinoic acid was dissolved in water with an equimolar amount of sodium hydroxide and adjusted to $\mathrm{pH} 7$.

\section{General procedures}

All animals were anesthetized with urethane $(1.2 \mathrm{~g} / \mathrm{kg}$, s.c.) and placed on a warm plate $\left(34^{\circ} \mathrm{C}\right)$. The left femoral vein and urinary bladder were catheterized for infusion of loading solution and collection of urine, respectively. The loading solution, containing $0.1 \%$ oxonate, $4 \%$ mannitol, $1.5 \%$ inulin, $0.03 \%$ sodium bicarbonate and $0.85 \%$ sodium chloride $(\mathrm{w} / \mathrm{v})$, was infused at a rate of $2.6 \mathrm{ml} / \mathrm{hr}$.
After equilibration for $60-90 \mathrm{~min}$, the effects of test drugs were examined.

\section{Uricosuric effect of E5050}

The effects of E5050, trichlormethiazide and probenecid on urate excretion were investigated by the clearance method in accordance with the experimental schedule shown in Fig. 1. In brief, a 10-min urine sample was collected, and test drugs were administered at the midpoint of the urine-collection period, at time 0 . A sample of blood was also taken two or three times, from the jugular vein, at the mid-point of the urine-collection period: once prior to administration of each drug and once or twice afterwards (from 25 to $35 \mathrm{~min}$ and from 85 to 95 min after administration of E5050, from 25 to $35 \mathrm{~min}$ after administration of trichlormethiazide and from 85 to $95 \mathrm{~min}$ after administration of probenecid), when uricosuric change was clearly observed in our preliminary study. Thus, to minimize the influence of blood loss via repeated sampling from one rat, the number of times of sampling was limited to a minimum. Plasma was collected immediately by centrifuging the blood at $1,500 \times g$ for $10 \mathrm{~min}$.

E5050 $(0.3,3,10$ or $15 \mathrm{mg} / \mathrm{kg})$ or trichlormethiazide $(0.1$ or $0.3 \mathrm{mg} / \mathrm{kg}$ ) was administered i.p. in a volume of 1 $\mathrm{ml} / \mathrm{kg}$. Probenecid $(100$ or $300 \mathrm{mg} / \mathrm{kg}$ ) was administered i.p. in a volume of $2 \mathrm{ml} / \mathrm{kg}$. The control animals received saline that contained $35 \%$ DMSO (DMSO/saline) instead of E5050 or trichlormethiazide, and they received a $1 \%$ solution of gum arabic instead of probenecid.

\section{Pyrazinoic acid suppression test}

In the pyrazinoic acid suppression test $(1,10)$, a 10 -min urine sample was collected three times: once prior to ad-

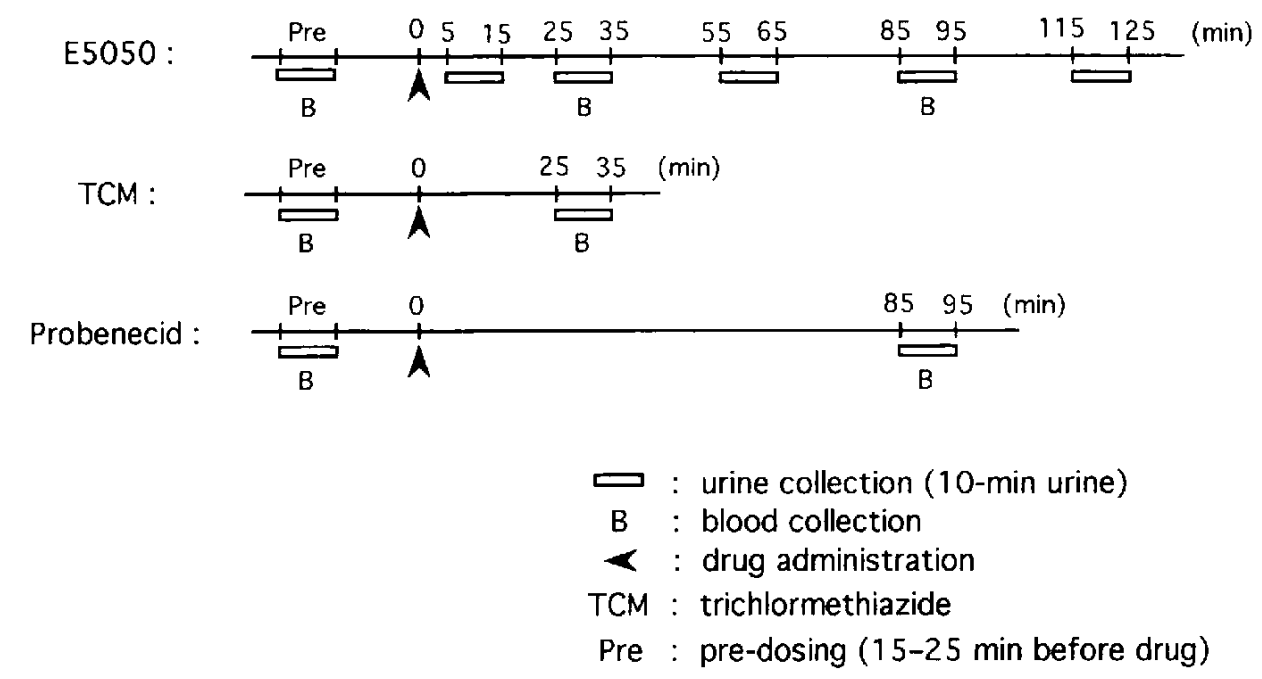

Fig. 1. Experimental schedules for clearance studies. 
ministration of E5050 and twice afterwards (from 25 to $35 \mathrm{~min}$ and from 55 to $65 \mathrm{~min}$ after E5050). E5050 (15 $\mathrm{mg} / \mathrm{kg}$ ) was administered i.p. in a volume of $1 \mathrm{ml} / \mathrm{kg}$ at time 0 . Pyrazinoic acid $(50 \mathrm{mg} / \mathrm{kg})$ was administered i.v., in a volume of $0.5 \mathrm{ml} / \mathrm{kg}, 2 \mathrm{~min}$ before the administration of E5050 and again $20 \mathrm{~min}$ later at the same dose in order to maintain pyrazinoic acid inhibition. The control animals received saline and DMSO/saline instead of pyrazinoic acid and E5050, respectively. Blood was collected at the midpoint of each urine-collection period as described above, and plasma was prepared by centrifugation.

\section{Influence of E5050 on urinary excretion of PSP}

In this study, E5050 (15 mg/ $\mathrm{kg})$ was given i.p., in a volume of $1 \mathrm{ml} / \mathrm{kg}, 20 \mathrm{~min}$ before administration of PSP and probenecid $(300 \mathrm{mg} / \mathrm{kg})$ was given, in a volume of 2 $\mathrm{ml} / \mathrm{kg}, 80 \mathrm{~min}$ before PSP. PSP $(0.1 \mathrm{ml} / \mathrm{kg})$ was administered i.v. at time 0 , and then urinary excretion of PSP was measured over the course of the next $15 \mathrm{~min}$. The control animals received DMSO/saline and a solution of gum arabic instead of E5050 and probenecid, respectively.

\section{Quantitations of urate, inulin and PSP}

Urate was quantitated by the phosphotungstate colorimetric assay with a Uric Acid-Test Wako Kit (Wako Pure Chemical Co., Osaka) since the animals received oxonate, a uricase inhibitor. Inulin was quantitated by the fluorometric method of Vurek and Pegram (11). PSP was quantitated colorimetrically at $559 \mathrm{~nm}$. The glomerular filtration rate (GFR) was calculated as the rate of inulin clearance.

\section{Statistical analyses}

The data are expressed as means \pm S.E. In the time course experiments, the data were analyzed by two-way analysis of variance followed by the paired $t$-test. In other experiments, the data were analyzed by the unpaired $t$ test.

\section{RESULTS}

\section{Effects of E5050 on the urinary excretion of urate}

The time-dependent effects of E5050 on the excretion of urate are shown in Table 1. In the control animals that received DMSO/saline, the rate of urinary excretion of urate (UURATE) and the urate clearance (CuRATE) increased slightly but significantly. The ratio of urate clear-

Table 1. Uricosuric effects of E5050 in rats

\begin{tabular}{|c|c|c|c|c|c|c|c|}
\hline & $\begin{array}{l}\text { Time } \\
(\mathrm{min})\end{array}$ & $\begin{array}{l}\text { Uvolume } \\
(i 1 / \mathrm{min})\end{array}$ & $\begin{array}{l}\text { UURATE } \\
(/ / \mathrm{g} / \mathrm{min})\end{array}$ & $\begin{array}{l}\text { PURATE } \\
\text { (mg/dl) }\end{array}$ & $\begin{array}{l}\text { CURATE } \\
(\mathrm{ml} / \mathrm{min})\end{array}$ & $\begin{array}{l}\text { CINULIN } \\
(\mathrm{ml} / \mathrm{min})\end{array}$ & Curate/Cinulin \\
\hline \multirow{4}{*}{ Control } & Pre & $17.3 \pm 2.0$ & $35.7 \pm 2.2$ & $2.26 \pm 0.27$ & $1.53 \pm 0.20$ & $1.92 \pm 0.20$ & $0.796 \pm 0.057$ \\
\hline & $25-35$ & $20.9 \pm 1.2$ & $37.6 \pm 2.3^{*}$ & $2.05 \pm 0.25$ & $1.79 \pm 0.25^{*}$ & $2.14 \pm 0.18$ & $0.817 \pm 0.070$ \\
\hline & $55-65$ & $21.4 \pm 1.5$ & $37.7 \pm 3.3$ & - & - & - & - \\
\hline & $85-95$ & $21.7 \pm 0.8$ & $37.0 \pm 2.1$ & $1.90 \pm 0.15$ & $1.84 \pm 0.20$ & $2.30 \pm 0.12$ & $0.805 \pm 0.084$ \\
\hline \multirow{5}{*}{$\begin{array}{c}\text { E5050 } \\
(10 \mathrm{mg} / \mathrm{kg})\end{array}$} & Pre & $16.2 \pm 0.8$ & $32.9 \pm 2.2$ & $2.30 \pm 0.37$ & $1.54 \pm 0.19$ & $2.12 \pm 0.09$ & $0.723 \pm 0.080$ \\
\hline & $5-15$ & $18.1 \pm 0.9$ & $35.4 \pm 1.9$ & - & - & - & - \\
\hline & $25-35$ & $21.3 \pm 2.2$ & $39.5 \pm 2.0^{* *}$ & $2.06 \pm 0.31$ & $2.05 \pm 0.24^{* *}$ & $2.16 \pm 0.13$ & $0.952 \pm 0.104^{* *}$ \\
\hline & $55-65$ & $21.6 \pm 2.5^{*}$ & $38.8 \pm 1.7^{* *}$ & - & - & - & - \\
\hline & $85-95$ & $23.2 \pm 1.7^{*}$ & $39.4 \pm 2.8^{*}$ & $1.92 \pm 0.31$ & $2.08 \pm 0.23^{* *}$ & $2.18 \pm 0.20$ & $0.962 \pm 0.087^{* *}$ \\
\hline \multirow{5}{*}{$\begin{array}{c}\text { E5050 } \\
(15 \mathrm{mg} / \mathrm{kg})\end{array}$} & $5-15$ & $20.6 \pm 3.1^{*}$ & $40.0 \pm 3.7^{*}$ & - & - & - & - \\
\hline & $25-35$ & $21.4 \pm 2.4^{* *}$ & $42.7 \pm 2.7^{*}$ & $1.83 \pm 0.19^{*}$ & $2.46 \pm 0.33^{* *}$ & $2.64 \pm 0.19^{*}$ & $0.925 \pm 0.091^{*}$ \\
\hline & $55-65$ & $21.3 \pm 2.8^{* *}$ & $38.5 \pm 2.0$ & - & - & - & - \\
\hline & $85-95$ & $19.9 \pm 3.1$ & $37.1 \pm 2.4$ & $1.63 \pm 0.10^{* *}$ & $2.31 \pm 0.21^{*}$ & $2.40 \pm 0.21$ & $0.970 \pm 0.057^{* *}$ \\
\hline & $115-125$ & $19.4 \pm 2.2^{*}$ & $37.5 \pm 2.2$ & - & - & - & - \\
\hline
\end{tabular}

E5050 (10 or $15 \mathrm{mg} / \mathrm{kg})$ was administered i.p. at time 0 . The control animals received vehicle instead of E5050. Data represent means \pm S.E. $(\mathrm{n}=5) .-$, Not determined. ${ }^{*} \mathrm{P}<0.05,{ }^{*} \mathrm{P}<0.01$ vs pre-dosing values (the paired $t$-test). Pre, Pre-dosing period (15-25 min before E5050 or vehicle). Other terms are defined in the text. 

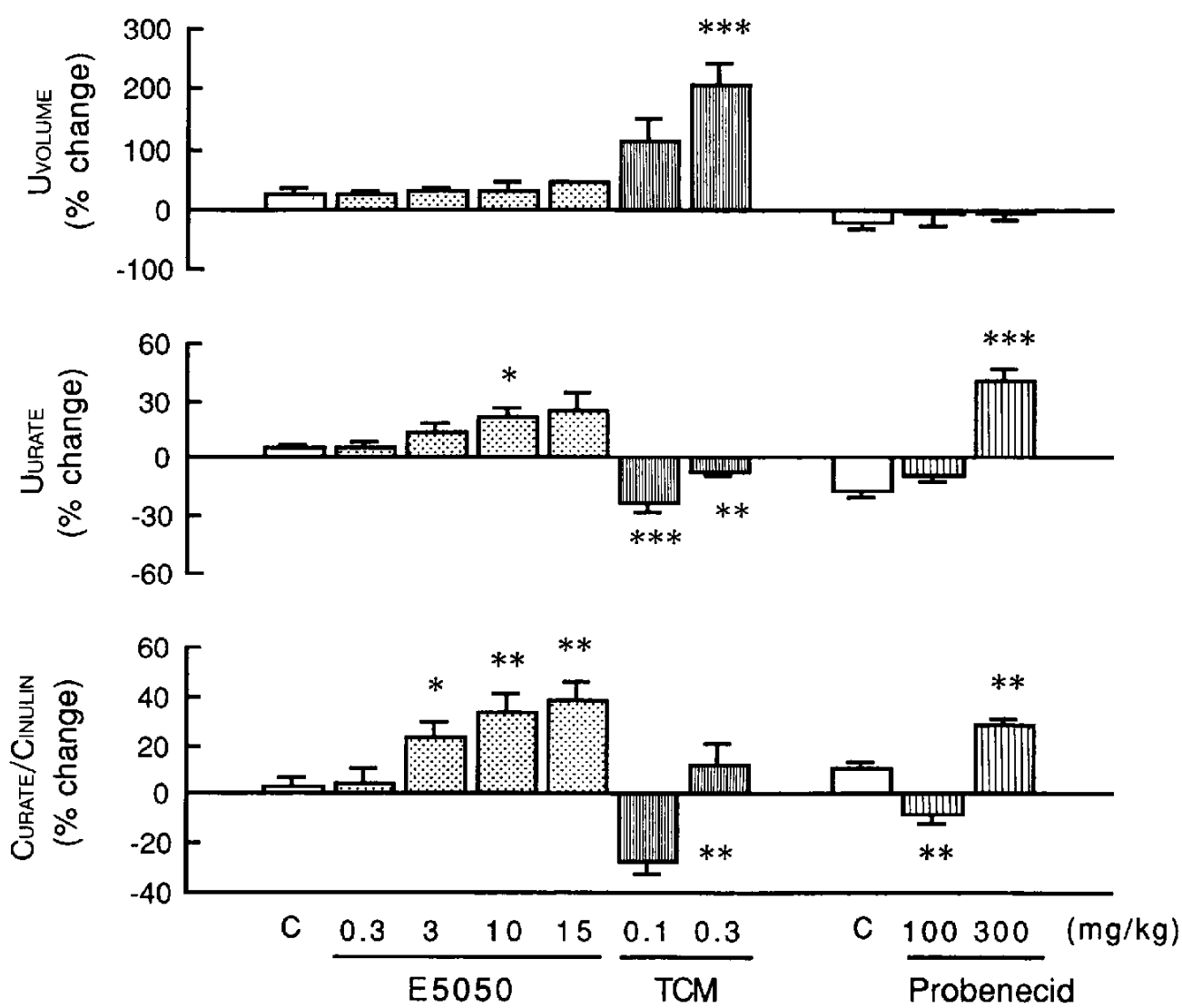

Fig. 2. Dose-dependent effects of E5050, trichlormethiazide (TCM) and probenecid on the urinary excretion of urate in rats. The control animals received the appropriate vehicle as follows: DMSO/saline instead of E5050 and TCM or a solution of gum arabic instead of probenecid. Uvolume, UURATE and Curate/Cinulin during the period from 25 to 35 min after administration of E5050, TCM or DMSO/saline and those during the period from 85 to $95 \mathrm{~min}$ after administration of probenecid or a solution of gum arabic are expressed as percentage changes relative to pre-dosing values, respectively. Data represent means \pm S.E. (ES050, $\mathrm{n}=5$; TCM, $\mathrm{n}=4-5$; probenecid, $\mathrm{n}=4$ ). ${ }^{*} \mathrm{P}<0.05,{ }^{* *} \mathrm{P}<0.01,{ }^{* * *} \mathrm{P}<0.001$ vs the corresponding control. C, Control.

ance to inulin clearance (Curate/Cinulin) and other parameters did not change significantly. When administered i.p. at a dose of 10 or $15 \mathrm{mg} / \mathrm{kg}$, E5050 was weakly diuretic and clearly uricosuric. Changes in urine volume (Uvolume) were moderate and had no apparent peak. A peak in UURATE was observed during the period from 25 to $35 \mathrm{~min}$ after administration of the drug, at both doses. Curate/Cinulin increased significantly at least from 30 to $90 \mathrm{~min}$ after administration. Levels of plasma urate (PURATE) did not change at the dose of $10 \mathrm{mg} / \mathrm{kg}$ and tended to decrease time-dependently at the dose of $15 \mathrm{mg} / \mathrm{kg}$.

The dependence on dosage of the effects of E5050, trichlormethiazide and probenecid on urate excretion is shown in Fig. 2. The dose dependence was examined when diuretic and uricosuric changes were clearly apparent after administration of the respective drugs, namely, during the period from 25 to $35 \mathrm{~min}$ after administration of E5050 or trichlormethiazide and during the period from 85 to $95 \mathrm{~min}$ after administration of probenecid.
E5050 at a dose of $0.3-15 \mathrm{mg} / \mathrm{kg}$ caused dose-dependent increases in Uurate and Curate/Cinulin. Changes in Uvolume were not significant. Trichlormethiazide caused diuresis in a dose-dependent manner. However, the influence of the drug on urate excretion was complex, as follows: Trichlormethiazide had a marked antiuricosuric effect at a dose of $0.1 \mathrm{mg} / \mathrm{kg}$ and attenuated its antiuricosuric effect at a higher dose of $0.3 \mathrm{mg} / \mathrm{kg}$. At the latter dose, UURATE increased transiently just after administration of the drug $(17.3 \pm 2.7 \%$ increase) and subsequently fell to below the pre-treatment level; decrease in UURATE during the period from 25 to $35 \mathrm{~min}$ after the administration was slight but significant, $-7.8 \pm 2.0 \%$. Changes in Curate/Cinulin during the same period were not significant. In contrast, probenecid at the lower dose of $100 \mathrm{mg} / \mathrm{kg}$ slightly, but significantly decreased Curate /Cinulin, but no decrease in Uurate was observed. At the higher dose of $300 \mathrm{mg} / \mathrm{kg}$, probenecid had a potent uricosuric effect that was accompanied by an increase in Curate/Cinulin; increases in Uurate and Curate 

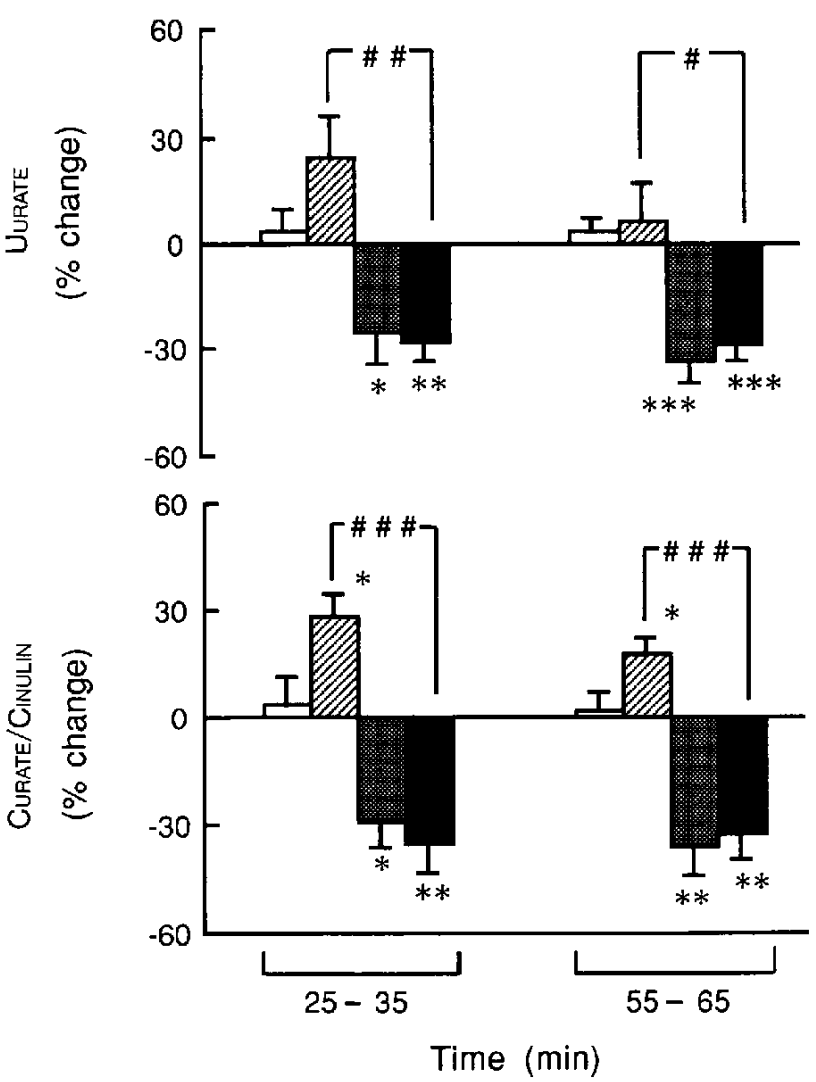

Fig. 3. The pyrazinoic acid (PA) suppression test in rats. UURATE and Curate/Crnulin during the period from 25 to $35 \mathrm{~min}$ after E5050 and during the period from 55 to $65 \mathrm{~min}$ after E5050 are expressed as percentage changes relative to pre-dosing values. Data represent means \pm S.E. (control $\square, n=5$; E5050 $n=4$; PA , $\mathrm{n}=5$; PA $+\mathrm{E} 5050 \square, \mathrm{n}=5$ ). ${ }^{*} \mathrm{P}<0.05,{ }^{* *} \mathrm{P}<0.01,{ }^{* * *} \mathrm{P}<0.001$ vs the control. ${ }^{*} \mathrm{P}<0.05,{ }^{n \prime \#} \mathrm{P}<0.01,{ }^{\# \# \#} \mathrm{P}<0.001$ vs the treatment with $\mathrm{E} 5050$.

/Cinulin during the period from 85 to 95 min after the administration were $39.7 \pm 7.4 \%$ and $27.5 \pm 3.3 \%$, respectively. Moreover, although the data are not presented, there was a slight initial decrease in CURATE/Cinuln during the period from 25 to $35 \mathrm{~min}$ after administration.

\section{Inhibitory effect of pyrazinoic acid on E5050-induced uricosuria}

To determine whether E5050 influences the secretion and/or the postsecretory reabsorption of urate in the tubules, we performed a pyrazinoic acid suppression test. The results of this test are summarized in Fig. 3. Pyrazinoic acid administered alone was markedly antiuricosuric; decreases in UURATE during the period from 25 to $35 \mathrm{~min}$ and during the period from 55 to $65 \mathrm{~min}$ after administration of the drug were $25.5 \pm 8.2 \%$ and $33.4 \pm 6.0 \%$, respectively; and those in CURATE/Cinulin during the same periods were $29.1 \pm 6.9 \%$ and $36.5 \pm 7.7 \%$, respectively. When administered in combina-
Table 2. Influence of E5050 and probenecid on urinary excretion of PSP in rats

\begin{tabular}{lcc}
\hline & Dose & $\begin{array}{c}\text { Recovery of PSP } \\
(\%)\end{array}$ \\
\hline Control & & $26.9 \pm 5.3$ \\
E5050 & $15 \mathrm{mg} / \mathrm{kg}$ & $28.7 \pm 7.3$ \\
Control & & $30.4 \pm 9.2$ \\
Probenecid & $300 \mathrm{mg} / \mathrm{kg}$ & $2.6 \pm 2.4^{* * *}$ \\
\hline
\end{tabular}

The control animals received the appropriate vehicle. Data represent means \pm S.E. $(n=6) .{ }^{* * *} \mathrm{P}<0.001$ vs the corresponding control.

tion with this pyrazinoic acid, E5050 completely lost its uricosuric effect. The extent of the decrease in UURATE and in Curate/Cinulin in the group treated with pyrazinoic acid plus E5050 was almost the same as in the group treated with pyrazinoic acid alone.

\section{Influence of E5050 on urinary excretion of PSP}

To determine whether E5050 stimulates the tubular secretion of organic anions including urate, the effects of E5050 and probenecid on the secretion of PSP were examined.

When E5050 and probenecid were administered separately, the maximum uricosuric response was observed $25 \mathrm{~min}$ and $85 \mathrm{~min}$, respectively, after i.p. administrations of the drug. Therefore, E5050 was administered 20 min before the injection of PSP and probenecid was injected $80 \mathrm{~min}$ before PSP and then the urinary excretion of PSP during a 15-min period was determined. The results are shown in Table 2. E5050 did not affect the urinary excretion of PSP. In contrast, probenecid markedly decreased such excretion.

\section{DISCUSSION}

In the present study, we examined the uricosuric effects of E5050 in rats during continuous i.v. loading with oxonate. Since the early report of Johnson et al. (12), oxonate-induced hyperuricemia in rats has been regarded as a good animal model for the evaluation of uricosuric drugs. The usefulness of this model has been supported by a micropuncture study (13) in which oxonate was shown not to influence CuRATE/CINULIN in rats. However, it was subsequently reported that oxonate inhibited urate uptake concentration-dependently in the brush border and basolateral membrane vesicles of rats (14) and further reported that Curate/Cinulin was decreased by oxonate in the isolated rat kidney (15). Our preliminary study using rats loaded i.v. with oxonate at various concentrations, from 0.025 to $0.5 \%(\mathrm{w} / \mathrm{v})$, also showed that oxonate increased CURATE/CINULIN dose-de- 
pendently at low concentrations and somewhat tapered the increase at over $0.1 \%$ concentration and that infusion of a solution of about $0.1 \%(\mathrm{w} / \mathrm{v})$ oxonate was sufficient for maintenance of hyperuricemia (data not shown). Moreover, in the other previous study (16), oxonate-treated rats responded to a uricosuric action of probenecid, but there was no paradoxical response. These rats received a higher dose of oxonate and were at higher levels of PURATE than rats loaded with $0.1 \%$ oxonate in our study. These findings indicate that excessive levels of oxonate might be unsuitable for evaluation of drugs.

Accordingly, to evaluate the uricosuric effect in rats of the new compound E5050, we had to confirm initially that rats loaded with $0.1 \%$ oxonate were sensitive to known drugs that affect renal urate transport, such as probenecid and trichlormethiazide. Under our experimental conditions, probenecid had a paradoxical effect in rats as it does in humans: the drug decreased Curate/CINULIN at a low dose and increased it at a high dose. Yonetani and Iwaki (16) reported that i.p. administration of trichlormethiazide at $0.5 \mathrm{mg} / \mathrm{kg}$, as a suspension in a solution of gum arabic, induced diuresis accompanied by uricosuria in oxonate-treated rats, but no biphasic response of uricosuria was apparent. In the present study, when administered i.p. as a solution in DMSO/saline, trichlormethiazide decreased Curate/Cinulin at a low dose of $0.1 \mathrm{mg} / \mathrm{kg}$ with an attenuated inhibitory effect on urate excretion at a high dose of $0.3 \mathrm{mg} / \mathrm{kg}$. At the latter dose, uricosuria was observed immediately after administration, although we could not obtain the clearance data during this initial period because of the very short duration of the uricosuric effect. Urate retention following uricosuria was probably due to its potent diuretic effect, as described in other reports that show that decreases in extracellular fluid volume caused by potent diuretics result in increased reabsorption of urate $(17,18)$. Thus, the uricosuric effect of trichlormethiazide was eventually overwhelmed by the antiuricosuric effect. Although the reason for the different results for trichlormethiazide remains unknown, it may be due to different experimental condjtions; for example, the vehicle for trichlormethiazide, the dosage form of trichlormethiazide (a liquid state or a solid state) and the dose of oxonate.

The effect of i.v. chlorothiazide on urate excretion is biphasic in Cebus monkeys (19) and humans (20). The use of DMSO as a solvent might explain the similarity between the results for trichlormethiazide administered i.p. and those for chlorothiazide administered i.v. DMSO stimulates the passage of other compounds across cell membranes, and as a consequence, test drugs are transferred promptly to the blood circulation.

As described by Dan et al. (5), it seems that the contribution of postsecretory reabsorption to the excretion of urate in the rat kidney is minor, and this contribution could explain the poor response to benzbromarone. However, even though the rat shows predominant presecretory reabsorption, poor secretion and poor postsecretory reabsorption of urate at normal or low plasma levels of urate, apparent secretion can be observed when Purate is maintained at high levels (13), as well as, apparently, postsecretory reabsorption. Therefore, we postulated that such hyperuricemic rats would respond to certain drugs that affect the secretory system or the postsecretory reabsorptive system for urate.

In a clinical study (9), E5050 was shown to inhibit the postsecretory reabsorption of urate and to induce moderate uricosuria. The present study demonstrated that i.p. administration of E5050 induced definite uricosuria in rats under oxonate loading. The uricosuric effect of E5050 was dose-dependent and we observed no paradoxical effect. The observation that E5050 increased Curate/CInUlin without any change in GFR indicates that the drug affects the urate-transport system in the rat renal tubules.

The pyrazinamide suppression test has been widely used to clarify the mechanisms of action of uricosuric drugs in clinical studies, but it is rarely used in studies with experimental animals $(21,22)$, presumably because only a few experimental animals, such as the chimpanzee, Cebus monkey and DBA/2N mouse (21), conform to the four-component hypothesis in the same manner as humans. In the present study with pyrazinoic acid, an active metabolite of pyrazinamide that is a selective inhibitor of the tubular secretion of urate, the uricosuric effect of E5050 was completely inhibited by pretreatment with pyrazinoic acid. This result indicates that the rat kidney, under appropriate conditions, could mimic to some extent the handling of urate by the human kidney, and it suggests that E5050 produces uricosuria via stimulation of tubular secretion or via inhibition of tubular postsecretory reabsorption in rats.

It is considered that PSP is secreted by a common transport system that operates with many organic anions, including $p$-aminohippurate (PAH) and penicillin, for example (23). Secretion of PAH and that of urate occur via different transport systems in rats $(24,25)$, but $\mathrm{PAH}$ appears to interfere with the secretion of urate at a high Purate level (26). Therefore, the results of the PSP test seem an acceptable source of indirect evidence of the effect of a drug on tubular urate transport. PSP, quantitated by a simple technique, showed, thus, to be useful compound for elucidating the mechanism of the tubular transport of urate, as indicated in previous studies (27, 28). In the PSP test, E5050 did not influence the urinary recovery of PSP, but probenecid markedly inhibited such recovery. The data are in good agreement with the finding 
that probenecid inhibited the transport of PSP (29), but benzbromarone did not (27). Accordingly, our results indicate indirectly that E5050 might exert its uricosuric action by decreasing the postsecretory reabsorption of urate rather than by increasing secretion. We do not yet know whether metabolites of E5050 are uricosuric.

In conclusion, rats loaded i.v. with oxonate at an appropriate dose respond to some uricosuric or antiuricosuric drugs in a similar manner to humans. The present study using this experimental animal model showed that E5050 is uricosuric in rats, and moreover, the results suggest that the mechanism of the uricosuric action of this drug involves inhibition of the postsecretory reabsorption of urate in the rat renal tubules.

\section{Acknowledgments}

The authors are grateful to Eisai Co. (Tokyo) for the gift of E5050.

\section{REFERENCES}

1 Levinson DJ and Sorensen LB: Renal handling of uric acid in normal and gouty subjects: evidence for a 4-component system. Annals Rheum Dis 39, 173-179 (1980)

2 Roch-Ramel F and Weiner IM: Renal excretion of urate: factors determining the actions of drugs. Kidney Int 18, 665-676 (1980)

3 Weiner IM: Urate transport in the nephron. Am J Physiol 237, F85-F92 (1979)

4 Diamond HS: Uricosuric drugs. In Uric Acid, Edited by Kelley WN and Weiner IM, pp 459-484, Springer-Verlag, Berlin, Heidelberg, New York (1978)

5 Dan T, Koga H, Onuma E, Tanaka H, Sato H and Aoki B: The activity of AA-193, a new uricosuric agent, in animals. Adv Exp Med Biol 253A, 301-308 (1989)

6 Moriwaki Y, Yamamoto T, Takahashi S, Suda M, Agbedana OE, Hada $T$ and Higashino $\mathrm{K}$ : Analysis of uric acid transport in renal tubules using benzbromarone and pyrazinamide. Adv Exp Med Biol 309A, 151-155 (1991)

7 Kramp RA and Lenoir R: Distal permeability to urate and effects of benzofuran derivatives in the rat kidney. Am J Physiol 228, 875-883 (1975)

8 Saeki T, Ohtsuka I, Hashida R, Shiojiri H, Yamatsu I, Morisaki N and Saito Y: The inhibitory effect of a novel antiatheromatous agent, E5050, on the intimal thickening of aorta in cholesterol-fed rabbit in vivo. Jpn J Pharmacol 56, 159-166 (1991)

9 Tanaka $T$, Tsutani $H$, Ueda $T$, Uchida $M$ and Nakanura $T$ : Hypouricemic effect of an antihyperlipidemic agent, $N-\{3-[4$ (2",6"-dimethylheptyl)phenyl]butanoyl $\}$-ethanolamine (E5050). Jpn J Clin Pharmacol Ther 23, 223-224 (1992) (in Japanese)

10 Diamond HS and Paolino JS: Evidence for a postsecretory reabsorptive site for uric acid in man. J Clin Invest 52, 1491-1499 (1973)

11 Vurek GG and Pegram SE: Fluorometric method for the determination of nanogram quantities of inulin. Anal Biochem 16,
$409-419(1966)$

12 Johnson WJ, Stavric B and Chartrand A: Uricase inhibition in the rat by s-triazines: an animal model for hyperuricemia and hyperuricosuria (33791). Proc Soc Exp Biol Med 131, 8-12 (1969)

13 De Rougemont D, Henchoz $\mathbf{M}$ and Roch-Ramel F: Renal urate excretion at various plasma concentrations in the rat: a freeflow micropuncture study. Am J Physiol 231, 387-391 (1976)

14 Abramson RG, King VF, Reif MC, Leal-Pinto E and Baruch SB: Urate uptake in membrane vesicles of rat renal cortex: effect of copper. Am J Physiol 242, F158-F170 (1982)

15 MacDougall ML and Wiegmann TB: Urate excretion by the isolated perfused rat kidney and modification by drugs (42997). Proc Soc Exp Biol Med 192, 276-280 (1989)

16 Yonetani $Y$ and Iwaki K: Effects of uricosuric drugs and diuretics on uric acid excretion in oxonate-treated rats. Jpn J Pharmacol 33, 947-954 (1983)

17 Steele TH: Evidence for altered renal urate reabsorption during changes in volume of the extracellular fluid. J Lab Clin Med 74, $288-299$ (1969)

18 Weinman EJ, Eknoyan G and Suki WN: The influence of the extracellular fluid volume on the tubular reabsorption of uric acid. J Clin Invest 55, 283-291 (1975)

19 Fanelli GM Jr, Bohn DL and Reilly SS: Renal effects of uricosuric agents in the Cebus monkey. J Pharmacol Exp Ther 175, 259-266 (1970)

20 Demartini FE, Wheaton EA, Healey LA and Laragh JH: Effect of chlorothiazide on the renal excretion of uric acid. Am J Med 32, $572-577$ (1962)

21 Dan T, Tanaka $H$ and Koga $H$ : Mechanism of uricosuric action of AA-193 in DBA/2N mice. J Pharmacol Exp Ther 253, $437-443$ (1990)

22 Iwaki $\mathrm{K}$ and Yonetani $\mathrm{Y}$ : Decreased renal excretion of uric acid following diuretic administration in rats. Jpn $\mathbf{J}$ Pharmacol $\mathbf{3 4}$ 389-396 (1984)

23 Maller JV and Sheikh MI: Renal organic anion transport system: pharmacological, physiological and biochemical aspects. Pharmacol Rev 34, 315-358 (1983)

24 Kramp RA and Lenoir RH: Characteristics of urate influx in the rat nephron. Am J Physiol 229, 1654-1661 (1975)

25 Kim YK, Jung JS and Lee SH: Uptake of uric acid and p-aminohippurate $(\mathrm{PAH})$ by renal cortical slices of various mammals. Comp Biochem Physiol 101A, 53-58 (1992)

26 Roch-Ramel $F$ and Peters G: Urinary excretion of uric acid in nonhuman mammalian species. In Uric Acid, Edited by Kelley WN and Weiner IM, pp 211-255, Springer-Verlag, Berlin, Heidelberg, New York (1978)

27 Politta G, Berthoud S, Gaudin G, Chavaz A and Fabre J: Mécanisme de l'action uricosurique de la benzbromarone. Schweiz Rundschau Med (PRAXIS) 62, $1345-1350$ (1973) (Abstr in English)

28 Yamamoto T, Maeda J, Moriwaki Y, Tamura S, Hada T, Higashino $\mathrm{K}$, Ogawa $\mathrm{K}$ and Yanagizawa $\mathrm{M}$ : The effect of zotepine on the excretion of purine bases. Uric Acid Res 9, 61-68 (1985) (Abstr in English)

29 Beyer $\mathbf{K}$ : Functional characteristics of renal transport mechanisms. Pharmacol Rev 2, 227-280 (1950) 